\title{
Quantitative assessment of right ventricular function in pectus excavatum
}

\author{
Rajeev L. Narayan, MD, ${ }^{\mathrm{a}}$ Prashant Vaishnava, MD, ${ }^{\mathrm{a}}$ Jose M. Castellano, MD, PhD, ${ }^{\mathrm{a}}$ and \\ Valentin Fuster, MD, PhD, ${ }^{\mathrm{a}, \mathrm{b}}$ New York, NY, and Madrid, Spain
}

Pectus excavatum is a common congenital chest wall deformity. ${ }^{1}$ Underlying cardiac chambers, in particular the right atrium and right ventricle (RV), may be compressed between the vertebral column and the depressed sternum in patients with this thoracic deformity. ${ }^{2}$ Citing improvement in indices of cardiovascular function after corrective surgery, some investigators have suggested that the deformed chest may contribute to cardiopulmonary impairment. ${ }^{3}$ Although cardiopulmonary impairment certainly may contribute to symptoms in patients with pectus excavatum and guide the need for and timing of corrective surgery, guidelines for the assessment of resting cardiovascular function remain undefined. Furthermore, the qualitative echocardiographic assessment of RV function and volumes among patients with pectus excavatum may be technically difficult and limited by subjectivity. ${ }^{1}$ Quantitative echocardiographic parameters, such as tricuspid annular plane systolic excursion (TAPSE) and RV fractional area change, may offer a more accurate assessment of $\mathrm{RV}$ function in this anatomically distinct population. ${ }^{4} \mathrm{Car}-$ diac magnetic resonance (CMR) imaging has emerged as the criterion standard in RV functional assessment and, more recently, has been validated in patients with pectus excavatum. ${ }^{5}$

We compared qualitative assessment of RV systolic impairment by visual echocardiographic inspection with quantitative assessment of $\mathrm{RV}$ function with $\mathrm{CMR}$ and echocardiographically derived TAPSE and RV fractional area change in a series of patients referred to our institution with mild to severe symptomatic pectus excavatum. Patients were being considered for corrective surgery. Our hypothesis was that the patients would be found to have normal RV function when assessed quantitatively, either through CMR or quantitative echocardiographic examination, despite impairment seen qualitatively.

\footnotetext{
From The Zena and Michael A. Wiener Cardiovascular Institute, ${ }^{a}$ The Mount Sinai Medical, Center, New York, NY; and the National Center for Cardiovascular Research (CNIC), ${ }^{\text {b Madrid, Spain. }}$

Disclosures: Authors have nothing to disclose with regard to commercial support.

Received for publication Nov 11, 2011; revisions received Dec 22, 2011; accepted for publication Jan 25, 2012; available ahead of print Feb 29, 2012.

Address for reprints: Prashant Vaishnava, MD, The Mount Sinai Medical Center, 1468 Madison Ave, Box 1030, New York, NY 10029 (E-mail: prashant. vaishnava@mountsinai.org).

J Thorac Cardiovasc Surg 2012;143:e41-2

$0022-5223 / \$ 36.00$

Copyright $(2012$ by The American Association for Thoracic Surgery

doi:10.1016/j.jtcvs.2012.01.073
}

\section{MATERIALS AND METHODS}

We evaluated 8 patients with pectus excavatum who were referred to our outpatient clinic for evaluation of dyspnea attributed to pectus excavatum and previous echocardiographic evaluation that had demonstrated qualitative RV dysfunction. All patients underwent 2-dimensional echocardiographic and CMR imaging at the Mount Sinai Medical Center in New York. The institutional review board was contacted, and formal approval was deemed unnecessary.

All patients in this series underwent 2-dimensional echocardiographic scanning with a Phillips iE33 xMATRIX Echocardiography System (Koninklijke Philips Electronics NV, Amsterdam, The Netherlands). Qualitative analysis of biventricular systolic function was performed by 1 of 3 trained echocardiographers. TAPSE was measured from the apical 4-chamber view as the maximum displacement of the lateral tricuspid annulus from diastole to systole in centimeters, with a TAPSE less than 16 mm indicative of RV systolic dysfunction. ${ }^{4} \mathrm{RV}$ fractional area change was measured as the difference between RV area in end-diastole and end-systole in the apical 4-chamber view, divided by the RV area in end-diastole, with RV fractional area change less than $35 \%$ indicative of RV systolic dysfunction. ${ }^{4}$ All patients underwent imaging with a 1.5-T (Magnetom Sonata; Siemens Medical Solutions USA, Inc, Malvern, Pa) or 3.0-T (Achieva; Koninklijke Philips Electronics) magnet, with dedicated surface coils and retrospective electrocardiographic gating.

\section{RESULTS}

All patients in this case series had RV dysfunction according to qualitative visual assessment. The range of dysfunction was graded from mild to severe. The sample was heterogeneous, with 5 men and 3 women ranging in age from 23 to 78 years. Average pectus index (maximum transverse diameter of the chest divided by the shortest sternospinal distance on $\mathrm{CMR}^{2}$ ) was $5.5 \pm 2.5$, consistent with at least moderate pectus deformity. As shown in Table 1, quantitative echocardiographic analysis demonstrated an overall normal TAPSE $(1.9 \pm 0.5 \mathrm{~cm})$ and RV fractional area change $(35.8 \% \pm 11.2 \%)$, and a normal RV ejection fraction was measured with CMR $(53.5 \% \pm 5.4 \%)$. None of the patients underwent corrective surgery.

\section{DISCUSSION}

Our results suggest that the qualitative echocardiographic evaluation of RV systolic function may be inaccurate and should not be used to inform the indication or timing of surgery. Quantitative echocardiographic assessment by measurement of RV fractional area change and TAPSE offers an alternative and potentially more accurate means of assessing $\mathrm{RV}$ function, equivalent to those derived from CMR imaging. Quantitative echocardiographic examination also offers the benefits of greater availability and less cost. 
TABLE 1. Summary of quantitative and qualitative measures of right ventricular function in patients with pectus excavatum by echocardiography and cardiac magnetic resonance imaging

\begin{tabular}{llccc}
\hline Patient & $\begin{array}{c}\text { RV } \\
\text { dysfunction* }\end{array}$ & $\begin{array}{c}\text { TAPSE } \dagger \\
(\mathbf{c m})\end{array}$ & $\begin{array}{c}\text { RV FAC } \dagger \\
(\%)\end{array}$ & $\begin{array}{c}\text { RV EF } \ddagger \\
(\%)\end{array}$ \\
\hline 1 & Severe & 1.8 & 17.8 & 47 \\
2 & Moderate & 2.5 & 25.5 & 59 \\
3 & Mild & 1.7 & 33.7 & 62 \\
4 & Moderate & 2.2 & 37.0 & 53 \\
5 & Moderate & 1.8 & 41.7 & 50 \\
6 & Moderate & 2.0 & 47.5 & 52 \\
7 & Moderate & 1.0 & 47.7 & 48 \\
8 & Mild & 1.9 & 36.0 & 54 \\
Mean \pm SD & NA & $1.9 \pm 0.5$ & $35.8 \pm 11.2$ & $53.5 \pm 5.4$ \\
Reference range & Normal & $1.5-2.0$ & $32-60$ & $49-72$ \\
$\quad$ in healthy & function & & & \\
subjects $\oint, \|$ & & & & \\
\hline
\end{tabular}

$R V$, Right ventricular; TAPSE, tricuspid annular plane systolic excursion; FAC, fractional area change; $E F$, ejection fraction; $N A$, not applicable. *Qualitative echocardiographic assessment of right ventricular dysfunction as mild, moderate, or severe. $\dagger$ By echocardiography. $\ddagger$ By cardiac magnetic resonance imaging. $§$ Rudski LG, Lai WW, Afilalol J, Hua L, Handschumacher MD, Chandrasekaran K, et al. ${ }^{4} \|$ Saleh RS, Finn JP, Fenchel M, Moghadam AN, Krishnam M, Abrazado M, et al. ${ }^{5}$

An accurate assessment of RV function in patients with pectus excavatum is imperative, because it may alter the decision for corrective surgery. Because of mixed data regarding whether there is measurable cardiopulmonary improvement postoperatively, there is no consensus as to the indications for corrective surgery for pectus excavatum. ${ }^{3}$ Nonetheless, an accurate assessment of biventricular function may help inform the need for surgery and clarify the etiology of symptoms in this anatomically distinct population. Although our case series is limited by a small heterogeneous sample size without a control population, we highlight a potentially important limitation of qualitative echocardiographic assessment when evaluating biventricular function.

\section{References}

1. Kelly RE Jr. Pectus excavatum: historical background, clinical picture, preoperative evaluation, and criteria for operation. Semin Pediatr Surg. 2008;17: 181-93.

2. Mocchegiani R, Badano L, Lestuzzi C, Nicolosi GL, Zanuttini D. Relation of right ventricular morphology and function in pectus excavatum to the severity of the chest wall deformity. Am J Cardiol. 1995;76:941-6.

3. Malek MH, Berger DE, Housh TJ, Marelich WD, Coburn JW, Beck TW. Cardiovascular function following surgical repair of pectus excavatum: a meta- analysis. Chest. 2006;130:506-16.

4. Rudski LG, Lai WW, Afilalo J, Hua L, Handschumacher MD, Chandrasekaran K, et al. Guidelines for the echocardiographic assessment of the right heart in adults: a report from the American Society of Echocardiography endorsed by the European Association of Echocardiography, a registered branch of the European Society of Cardiology, and the Canadian Society of Echocardiography. J Am Soc Echocardiogr. 2010;23:685-713; quiz, 786-8.

5. Saleh RS, Finn JP, Fenchel M, Moghadam AN, Krishnam M, Abrazado M, et al. Cardiovascular magnetic resonance in patients with pectus excavatum compared with normal controls. J Cardiovasc Magn Reson [serial online]. Available from: http://jcmr-online.com/content/pdf/1532-429X-12-73.pdf. December 13, 2010;12:73. Accessed August 1, 2011.

\title{
A new echocardiographic window to visualize the mitral valve complex during mitral valve repair for functional mitral regurgitation
}

\author{
Kikuko Obase, MD, PhD, ${ }^{\mathrm{a}}$ Masashi Komeda, $\mathrm{MD}, \mathrm{PhD},{ }^{\mathrm{b}}$ Hiroyuki Okura, $\mathrm{MD}, \mathrm{PhD},{ }^{\mathrm{a}}$ and \\ Kiyoshi Yoshida, MD, PhD, ${ }^{\text {a }}$ Kurashiki and Nagoya, Japan
}

Reconstructive surgery, which restores the normal alignment between the mitral annulus and displaced papillary muscles (PMs), might be beneficial in patients with functional mitral regurgitation (MR). A detailed understanding

From the Department of Cardiology, ${ }^{\text {a }}$ Kawasaki Medical School, Kurashiki, Japan; and Department of Cardiovascular Surgery, ${ }^{\mathrm{b}}$ Nagoya Heart Center, Nagoya, Japan Disclosures: Authors have nothing to disclose with regard to commercial support.

Received for publication Nov 14, 2011; revisions received Jan 11, 2012; accepted for publication Jan 24, 2012; available ahead of print Feb 20, 2012.

Address for reprints: Kikuko Obase, MD, PhD, Department of Cardiology, Kawasaki Medical School, 577 Matsushima, Kurashiki 701-0192, Japan (E-mail: obasekkk@ med.kawasaki-m.ac.jp).

J Thorac Cardiovasc Surg 2012;143:e42-4

$0022-5223 / \$ 36.00$

Copyright (C) 2012 by The American Association for Thoracic Surgery

doi:10.1016/j.jtcvs.2012.01.064 of the mitral apparatus is the key to successful surgery. Although 3-dimensional transesophageal echocardiography (3D-TEE) plays an essential role in understanding the mitral valve apparatus, the conventional trans-left atrial (LA) observation by 3D-TEE sometimes fails to visualize the subvalvular apparatus. When assisting surgical subvalvular reconstruction, it is imperative to obtain appropriate images for quantitative analysis of the submitral morphology. In the present study, we compared the effectiveness of the transgastric approach using 3D-TEE in visualizing the mitral valve structure with the conventional trans-LA approach during surgery for functional MR.

\section{METHODS}

A total of 8 consecutive patients ( 2 with chronic atrial fibrillation) underwent mitral valve surgery for functional MR. After anesthesia induction 